\title{
ВИРТУАЛЬНЫЙ СКРИНИНГ ЛЕКАРСТВЕННЫХ СОЕДИНЕНИЙ НА ПОТЕНЦИАЛЬНУЮ ВОЗМОЖНОСТЬ САМОСБОРКИ В СУПРАМОЛЕКУЛЯРНЫЕ НАНОАГРЕГАТЫ
}

\author{
Д.А. Горшенин, А.С. Бабушкин \\ Кафедра органической химии, ВолгГТУ, \\ 400005, Россия, г. Волгоград, проспект им. В.И. Ленина, 28.
}

DOI: 10.19163/MedChemRussia2021-2021-395

E-mail:n33g@yandex.ru

Метод виртуального скрининга широко применяется для автоматизированной оценки низкомолекулярных органических соединений на биологическую активность в процессе разработки новых лекарственных веществ [1]. В тоже время, аналогичная автоматизированная оценка низкомолекулярных соединений с не меньшим успехом может быть использована для поиска перспективных веществ и в других прикладных областях, в которых достаточно просто формализовать свойства, имеющие определяющее значение для данной области [2]. В том числе, очевидно, такая зависимость может быть выявлена и в отношении потенциальной способности низкомолекуляных соединений к самосборке в супрамолекулярные наноагрегаты, хотя пока нам не удалось найти соответствующих примеров в научной литературе. Нас особо интересует возможность формирования наноагрегатов именно из лекарственных соединений, поскольку они могут найти применение в качестве средств самодоставки [3]. В связи с вышеизложенным, мы предполагаем использовать аналог метода виртуального скрининга в сочетании с методами хемоинформатики для поиска в базах данных лекарственных соединений, возможно обладающих интересующим нас свойством. Если таковые соединения будут найдены, в дальнейшем мы планируем исследовать наноагрегаты, теоретически образующиеся из данных соединений, с применением более точных методов молекулярного моделирования, например, квантово-химических.

\section{Литература}

[1] I. Muegge and S. Oloff, Drug Discov. Today. 2006, 3, 405-411.

[2] D.P. Tabor, L.M. Roch, S.K. Saikin et al., Nat Rev Mater. 2018, 3, 5-20.

[3] S.-Y. Qin, A.-Q. Zhang, S.-X. Cheng, L. Rong and X.-Z. Zhang, Biomaterials. January 2017, 112, 234-247. 